\title{
Estado de Derecho y Desobediencia civil
}

\author{
Carlos F. Pressacco
}

Universidad Alberto Hurtado, Santiago, Chile. Email: fpressac@uahurtado.cl

Resumen: Los actos de desobediencia civil son parte de un estado de derecho democrático y se desarrollan en sociedades maduras que logran procesar sus conflictos aceptando que las leyes e instituciones legalmente establecidas pueden “fallar”, admitiendo un espacio para la construcción de interpretaciones distintas a las predominantes que, sin embargo, pretenden ser consideradas justas. La opinión generalizada de que todo acto contrario a la ley es siempre un acto ilegal que merece tanto el castigo positivamente definido como la condena social, admite otro análisis desde la perspectiva de la desobediencia civil. En primer lugar, presentamos un análisis del debate sobre los fundamentos del poder legítimo. En segundo lugar, una reflexión sobre las limitaciones que desde las ciencias sociales y el derecho se presentan para aportar una comprensión diferente sobre la desobediencia civil. Finalmente, un recorrido conceptual por distintos autores que analizan el concepto de desobediencia civil.

der - autoridad

Palabras clave: Desobediencia civil, estado de derecho, legitimidad, po-

\section{Rule of Law and Civil Disobedience}

\begin{abstract}
Acts of civil disobedience are part of a democratic rule of law and develop into mature societies that manage to process their conflicts by accepting that legally established laws and institutions can «fail», admitting a space for the construction of interpretations that differ from the prevailing whixh, nevertheless, claim to be fair. The widely held view that any act contrary to the law is always an illegal act that deserves punishment, both positively defined as well as social condemnation, admits another analysis from the perspective of civil disobedience. First, we present an analysis of the debate on the foundations of legitimate power. Second, an analysis of the limitations that from social sciences and law arise, in order to provide a different understanding of civil disobedience. Finally, a conceptual revision of different authors that examine the concept of civil disobedience.
\end{abstract}

Key words: Civil disobedience, rule of law, legitimacy, power, authority

\section{Estado de Direito e desobediência civil}

Resumo: Os atos de desobediência civil fazem parte de um Estado democrático de direito e se desenvolvem em empresas maduras que conseguem processar os seus conflitos, ao aceitar que as leis e as instituições legalmente constituídas podem “falhar", admitindo um espaço para a construção das interpretações vigentes que, contudo, afirmam ser considerado justo. A visão amplamente difundida de que qualquer ato contrário à lei é sempre um ato ilegal que merece punição, tanto positiva definida como a condenação social, admite uma outra análise a partir da 
perspectiva da desobediência civil. Primeiro, apresentamos uma análise do debate sobre os fundamentos do poder legítimo. Em segundo lugar, uma reflexão sobre as limitações das ciências sociais e direito são apresentadas para proporcionar uma compreensão diferente de desobediência civil. Finalmente, um conceitual de diferentes autores que analisam o conceito de desobediência civil.

der, autoridade

Palavras-chave: desobediência civil, Estado de direito, legitimidade, po-

\section{¿De qué se trata?}

Hacia finales de la década del '50 del siglo XIX, Henry Thoreau, un ciudadano estadounidense de origen francés residente de la localidad de Concord, cercana a Boston, escribió un pequeño documento denominado “Desobediencia Civil”. Thoreau, una persona considerada excéntrica, de ácidas reflexiones e ingenio inagotable, que había estudiando en Harvard, elaboró su reflexión a partir de su rechazo a pagar un impuesto del gobierno de la época destinado a financiar la guerra de Texas contra México, decisión por la cual fue encarcelado y de donde solo salió cuando sus amigos cancelaron la deuda.

Los motivos de Thoreau eran más profundo y apelaban a razones que iban más allá del egoísmo individualista; cuestionaba la legitimidad del gobierno para cobrar impuestos que financiaban una guerra que él consideraba injusta y, que además, avalaba la esclavitud: "ni por un momento puedo reconocer esa organización política como mi gobierno, mientras sea igualmente el gobierno de los Estados que mantienen la esclavitud” (Thoreau 2006: 42)

El cuestionamiento de Thoreau no apunta a aquellos sistemas políticos que son abiertamente totalitarios ya que allí se hace evidente el deber ciudadano de no obedecer e incluso de resistirse violentamente a al gobierno; está pensando fundamentalmente en gobierno democráticos y representativos, que surgidos de la voluntad popular y sostenidos en el estado de derecho, tienen en los rincones de su legalidad normas o prácticas que no coinciden con el sentido de justicia de los ciudadanos.

Con ello, Thoreau se inscribe en una fuertemente anclada tradición del pensamiento occidental que se ocupa de la legitimidad del poder político, de la razones a las que puede apelar el gobierno para exigir obediencia y del espacio de los ciudadanos para desplegar su subjetividad en la frontera entre la legalidad y legitimidad.

Se trata de un asunto que ha sido objeto de una dilatada reflexión y que recobró relevancia hacia finales de la década del '60 y principios de la del '70 en el marco del desarrollo de los movimientos contraculturales y, mas recientemente, a partir de la crisis de legitimidad de las democracias. 
Los interrogantes apuntan a la compatibilidad entre el ejercicio de la desobediencia y la vigencia de un régimen democrático que garantiza la existencia de libertades, derechos y garantías a todos sus ciudadanos; ¿no puede ser acaso la desobediencia un obstáculo al proceso de consolidación de la democracia en la medida que ella puede desencadenar dinámicas especialmente corrosivas en contextos de fragilidad institucional?

Lo que sigue es un intento por demostrar que, contrariamente a lo que se piensa habitualmente, los actos de desobediencia civil son parte de un estado de derecho democrático y se desarrollan en sociedades maduras que logran procesar sus conflictos aceptando que las leyes e instituciones legalmente establecidas pueden "fallar" admitiendo un espacio para la construcción de interpretaciones distintas a la predominantes que, sin embargo, pretenden ser consideradas justas.

Sociedades en donde los ciudadanos tienen el derecho a cuestionar las decisiones tomadas de acuerdo a los procedimientos consagrados en la constitución y las leyes por los poderes legítimamente constituidos a partir del ejercicio soberano de la ciudadanía por medio de los mecanismos democráticos tradicionales.

Si ello es así en las denominadas sociedades democráticas maduras donde efectivamente operan un conjunto de derechos y libertades, más pertinente parece aún en sociedades como las latinoamericanas en donde el estado de derecho dista mucho de ser una realidad efectiva. Incluso desde los mínimos democráticos que Dahl incorpora en su concepto de poliarquía. Piénsese en el caso de nuestro país o el de otros países de América Latina como Colombia, Paraguay, Brasil, Argentina u otros estados centroamericanos- que cuenta con una constitución aprobada en 1980 en el contexto del régimen autoritario y que si bien has sido sujeta a un conjunto de reformas, sigue siendo fundamentalmente el mismo texto. $\mathrm{U}$ otros ejemplos que apuntan, también en el caso de nuestro país, a las debilidades de los derechos laborales (prácticas antisindicales, por ejemplo) o de los derechos políticos cuando se exige el trámite de la inscripción previa o la imposibilidad de votar a los chilenos residentes en el extranjero.

Dicho de otra manera, en un contexto marcado por la debilidad del estado de derecho, de profundas inequidades y concentración de la riqueza, cabe preguntarse hasta que punto la ciudadanía puede sin más confiar en la calidad democrática de las instituciones representativas y los poderes del estado.

Un punto de vista como el que presentamos acá aporta una mirada distinta sobre aquellos actos que desafían a la legalidad vigente, asunto especialmente importante en un momento en el cual diversos análisis auguran un incremento de la conflictividad social. La opinión generalizada de que todo acto contrario a la ley es simple y llanamente un acto ilegal que merece tanto el castigo positivamente definido, pero además, la condena social, admite otro análisis desde la perspectiva de la desobediencia civil. 
Aporta un instrumental para distinguir aquellas conductas delictuales de otras que siendo legalmente delitos admiten otra interpretación.

En el trasfondo de tales posiciones -que se encuentran ampliamente distribuidas, atravesando los más variados sectores políticos y sociales- se encuentra la certeza de que en el contexto de un régimen democrático, la confianza de la sociedad en el funcionamiento eficiente y justo de los mecanismos institucionales debe ser un "cheque en blanco" que la ciudadanía le entrega a los poderes del Estado. El mismo sistema permite, en caso de ser un ciudadano defraudado, corregir la situación optando en la próxima elección por otro candidato con un programa de gobierno distinto. Existe un fuerte rechazo a cualquier intento por cuestionar la institucionalidad -en aquella parte de ella que como precisa Bobbio (Bobbio 1988) son las reglas del juego y no las reglas básicas que permiten el desarrollo del juego mismo- apelando a mecanismos extralegales.

Esta perspectiva aporta una mirada estrecha que limita las posibilidades teóricas y prácticas que brinda el Estado de Derecho y la necesaria mínima coherencia que deben tener los cambios socio-culturales con la estructura institucional. Nuestra perspectiva surge allí donde el Estado de Derecho acepta la tensión entre legitimidad y legalidad, donde existe la posibilidad cierta del error en la administración de la justicia, donde se acepta también la necesidad que tenemos de reconocer ese error si es que queremos alcanzar la justicia, allí donde bajo ciertas condiciones, esos errores y fallas, intenten ser corregidos apelando a instrumentos extralegales como puede ser la desobediencia.

El recorrido de este texto reconoce tres grandes apartados. En primer lugar, un análisis del debate sobre los fundamentos del poder legítimo con el contexto político y de sus transformaciones como telón de fondo. En segundo lugar, una reflexión sobre las limitaciones que desde las ciencias sociales y el derecho se presentan para aportar una comprensión diferente sobre la desobediencia civil. Finalmente, un recorrido conceptual por distintos autores que analizan la desobediencia civil: Hannah Arendt, Jurgüen Habermas, Ronald Dworkin, John Rawls y Peter Singer.

\section{Sobre el fundamento de la legitimidad}

Durante siglos, y desde diferentes perspectivas teóricas, la teoría política ha colocado en el centro de sus reflexiones su preocupación por la legitimidad del poder político: cual es el fundamento que permite que el gobierno pueda "mandar" a la ciudadanía y en virtud de cuales argumentos la ciudadanía puede estar disponible para obedecer al gobierno.

Esto es lo que Bobbio define como el problema de la "obligación política” que puede ser analizado tanto desde la perspectiva "de las razones por las cuales se obedecen las ordenes de quien detenta un cierto tipo de poder o como determinación de los casos en los cuales se debe obedecer y 
de los casos en los que es lícita la desobediencia o la obediencia pasiva” (Bobbio 1988: 118).

Como afirma Foucault (1978), gran parte del esfuerzo teórico de Occidente ha estado dedicado a establecer los puentes entre el derecho y el poder político de tal manera de fortalecer las posibilidades del poder de exigir obediencia por parte de la ciudadanía y, por otro lado, hasta donde los ciudadanos están obligados a obedecer.

El abordaje del problema reconoce dos grandes tradiciones teóricas. Por un lado, las que afirman que el poder político requiere un principio a partir del cual se fundamenta su legitimidad y que permite distinguirlo de su mero ejercicio fáctico, y por otro lado, los que sin desconocer que el poder cuenta con algún tipo legitimidad, centran el análisis en su efectividad.

El mismo Bobbio presenta tres principios fundantes de la legitimidad, los cuales dan lugar a tres pares de alternativas: el principio de la voluntad, admite que el poder esté fundado en la voluntad divina o la voluntad del pueblo; el principio de la naturaleza, que funda el poder, o bien en el hecho natural de que existen personas fuertes y débiles (y que son las primeras las que ejercen el poder) o bien en el ejercicio racional del poder a partir del cual la labor del gobierno es “descubrir” las leyes naturales; finalmente, está el principio fundante a partir de la historia ya sea apelando al pasado de las tradiciones (típico del pensamiento conservador) o echando mano al futuro legitimando el poder en un proyecto que se despliega gradualmente en el tiempo (propia del pensamiento revolucionario).

Tal vez una de las razones por las cuales el tema de la desobediencia despierta la sensibilidad y suspicacia de vastos sectores -especialmente de aquellos vinculados a los diferentes ámbitos del poder-, sea el hecho de que se encuentra ampliamente extendida esa conceptualización que define a la relación política como una relación de "mando y obediencia” en donde la pregunta por el fundamento de la legitimidad del poder queda desplazada por el énfasis en la consideración como un hecho desprovisto de valoraciones.

Es Weber el mejor representante de esta tradición, quien se centra en observar los argumentos que las sociedades emplean para justificar el poder y, si bien no se pueden hacer distinciones tajantes, presenta tres grandes conjuntos de razones: la tradición, el carisma y la que prevalece desde la modernidad, la legal racional.

Conviene señalar algo que a veces se deja de lado: que esta relación política de dominación (mando y obediencia) está sujeta a ciertas condiciones: el mandato se refiere a personas específicas, en el marco de un territorio determinado, sobre materias preestablecidas. No se puede exigir -ni esperar obediencia- más allá de estos límites.

Modernamente, dos elementos se amalgaman en la determinación de dichos límites: por un lado, la voluntad soberana expresada por medio 
del derecho de sufragio cada vez mas extendido; por otro lado, y como resultado de esa voluntad soberna, la ley. De tal manera que se exige y se brinda obediencia en virtud de aquello consagrado legalmente. Ello porque, si bien Weber reconoce que la legitimidad de un orden tiene origen en el carisma, las tradiciones y en lo establecido legalmente, establece que modernamente la última es la modalidad predominante (Weber 1988).

Sin embargo, mas allá de las precisiones por el mismo Weber señaladas, es necesario destacar que esta significación tiene variadas consecuencias:

a) En primer lugar, enfatizar el componente de mando y obediencia empuja a un segundo plano el problema de cómo se constituye el poder y deja de lado el hecho que el poder es una capacidad de la comunidad o del grupo y no la facultad de una persona o de un grupo de personas.

b) En segundo lugar, referirse al poder como un problema de mando y obediencia supone una visión un tanto militarizada de la política que retroalimenta los fundamentos de un estrecho vínculo entre política y violencia -desconocida por lo griegos antiguos- de tal modo que la guerra se transforma en la continuación de la política pero por otros medios.

c) En tercer lugar, si el poder político consiste en mandar y obedecer, lo fundamental es la eficiencia que como mandatario logre conseguir, asumiendo que la eficiencia se "mide" por el grado de obediencia: "si la esencia del poder es la eficacia del mando, entonces no hay poder más grande que el que emana del cañón de un arma, y sería muy difícil decir en que forma difiere la orden dada por un policía de la orden dada por un pistolero” (Arendt 1988: 140).

d) Finalmente, asumir unilateralmente la relación política como "mando y obediencia” supone un desconocimiento de la soberanía popular en tanto los que mandan son el gobierno y los que obedecen son los gobernados, cuando el principio de la soberanía popular sostiene lo contrario. Si bien nadie niega abiertamente, en el marco de un régimen democrático, la validez de éste principio. Sin embargo, ello no elimina para nada los pequeños grandes desconocimientos cotidianos y la violación de éste principio en manos de estructuras burocrático-administrativas.

La gran limitación de este planteo es que "al procurar un concepto científico y neutral de legitimidad, las teorías que siguen en la estela weberiana no poseen forma de considerar ilegítima a una autoridad que ha conseguido reconocimiento mediante la manipulación, a la que han dado una apariencia de legalidad” (Del Aguila 1997:29).

Otra observación es aquella que se relaciona con el fundamento 
mismo de la legalidad. Habitualmente se argumenta obedecer aquellas leyes que siguiendo el procedimiento legalmente establecido, han sido aprobadas por el Parlamento integrado por representantes elegidos por la ciudadanía en elecciones libres, transparentes y competitivas. Se supone que el cumplimiento del proceso e instituciones democráticas garantiza el sentido democrático de las leyes. Pero las garantías que el cumplimiento de dicho proceso ofrece, puede ser cuestionado al menos desde tres perspectivas: a) el sentimiento de crisis que afecta a la representación política y la manera en que funciona el sistema de partidos; b) la sospecha de que la complejidad de los temas y el relativamente bajo número de parlamentarios involucrados en las decisiones incrementan las posibilidades de error; c) la creciente falta de un espacio público de deliberación ciudadana (Tenzer, 1991).

Un ejemplo de lo señalado es la forma en que funciona el sistema de partidos y como este procesa las demandas ciudadanas expresadas en el voto. El perfil de los partidos políticos en la actualidad coincide con lo que se conoce como partidos atrapa-todo. El actuar de estos partidos privilegia el cálculo electoral (la maximización de los votos) sobre la base de plataformas ambiguas y generales. Esto último les permite "disponer” del sufragio popular en las negociaciones con otros partidos y de esa manera el sufragio pasa a ser considerado del mismo modo a como es tratado el depósito en un banco (Lechner 1984).

Podría decirse que la relativa escasa complejidad de nuestras instituciones -si comparamos la institucionalidad de principios de siglo con la vigente hoy en día, claramente podemos observar que para nada se relaciona con los cambios operados en el campo tecnológico y cultural- debiera traducirse en un mayor volumen de "fallas" en el sistema, y el reconocimiento de este hecho debiera estimularnos a aceptar caminos alternativos para hacer presentes dichas "fallas".

Por lo tanto, en el plano de ciertas concepciones, una visión "militarizada" de la política y el sentido que en la actualidad posee el funcionamiento del sistema político y su impacto en el proceso de constitución de las leyes, incrementan a nuestro juicio las posibilidades de que procedimientos legales y democráticos den por resultado decisiones -o falta de ellas- parcialmente injustas que afecten al conjunto o a una parte de la sociedad. Hablamos de decisiones parcialmente injustas porque suponemos que en el contexto de un régimen democrático en donde el conjunto de las instituciones tiene un funcionamiento razonable, no es posible obtener como resultado decisiones "totalmente injustas".

Relacionado con esto que hemos señalado respecto a las leyes y al funcionamiento del sistema político, está lo referido por Loewenstein respecto a las constituciones:"si al principio, un documento constitucional formal servía para limitar el ejercicio del poder, la existencia hoy de una constitución escrita no implica, en absoluto, ipso facto una garantía de distribución y, por lo tanto, limitación del poder” (Loewenstein 1983:124). 
Esta crisis de la democracia y de la constitución genera una creciente indiferencia frente a la constitución, lo cual se halla estrechamente vinculado con el debilitamiento de su observancia por parte de los detentadores del poder.

Estos aspectos problemáticos adquieren en Chile -y en general en América Latina- un significado distinto debido a la simultaneidad del proceso de modernización que ha privilegiado unilateralmente su racionalidad técnico-instrumental (incorporación de tecnología, incremento del consumo, agudización de la fragmentación social, integración internacional) dejando de lado o limitando al máximo todo aquel significado mas universal de lo moderno que fundamentalmente ligado con la racionalidad normativa y con el desenvolvimiento de la política y de la ciudadanía como ámbitos de autodeterminación. Por ello es que no debe sorprendernos que tal unilateralidad se traduzca también en el predominio de la economía y el mercado por sobre la política: un rol cada vez mas reducido del Estado, un fortalecimiento sesgado de actores sociales, cuestionamientos permanentes al gasto social, presión por privatizar empresas, es decir, el creciente tratamiento de los asuntos públicos como asuntos técnicos.

El objetivo inmediato de estas tendencias es el repliegue del Estado a las funciones mínimas y la privatización tanto de sus activos como de sus decisiones en los ámbitos de la asignación de recursos, la inversión productiva y determinación de precios e ingresos; el objetivo último es lograr la primacía del sector privado y estructurar una sociedad de mercado (....) este concepto de Estado subsidiario afirma la supremacía de la lógica económica por sobre la lógica política considerando a la primera como fuente de racionalidad y modernización mientras que la segunda como un anacronismo generador de ineficiencia, distorsión y estancamiento (Muñoz 1992).

Si bien hay un cierto consenso sobre el fin de la transición política en nuestro país, lo que también parece claro es que el sistema político habiendo disminuido el porcentaje de personas en situación de pobreza y la indigencia y desarrollando iniciativas orientadas ha recuperar parte del rol del estado en ámbitos como la salud, la educación y la previsión social, ha tenido escasos avances en lo que se refiere a mejorar la equidad en la distribución del ingreso.

En este contexto, es posible que se intensifiquen las manifestaciones de descontento ciudadano y no parece recomendable colocar a todas ellas bajo un mismo prisma. Para ello es necesario disponer de un instrumental que permita distinguir entre los actos de violencia y de tipo delictual de aquellos que sea manifiestan como desobediencia -no como violencia-, es decir como un síntoma de sanidad de una sociedad que en situaciones críticas y conflictivas valora la importancia de la ley pero que se coloca frente a ella cuestionándola en alguna de sus manifestaciones concretas.

Sin embargo, en el cuadro cultural predominante, tales expresiones tienden a ser consideradas como "anormales" y obstaculizadoras del proceso de democratización. Pero como ya señalamos anteriormente, tales in- 
terpretaciones no se deben a una especie de "perversa manía represiva” sino a una determinada manera de concebir el orden, la sociedad, y en definitiva al ser humano.

Esta compleja amalgama posee al menos dos elementos reforzadores: uno que proviene del campo de las ciencias sociales, y otro que se origina en el campo de las ciencias jurídicas.

Empecemos por el primero. La reflexión y análisis en el campo de las ciencias sociales tiene como punto central la manera en que nos apropiamos y conocemos a la realidad. Ello afecta toda nuestra experiencia de vida, nuestra vida cotidiana, etc. Específicamente en el campo de la ciencia política, desde el conductismo a la teoría de los juegos pasando por el marxismo -si bien es cierto que los enfoques abordados contienen perspectivas y énfasis distintos-, todos los enfoques coinciden en pertenecer a una época en que las ciencias tenían certezas respecto al futuro o destino final de las sociedades.

La claridad respecto del futuro presiona a su vez por considerar la libertad del otro como un obstáculo a controlar; mientras mas control tengamos sobre las voluntades ajenas, más fácilmente lograremos la meta. Para controlar la libertad del otro, y de esa manera reducir la incertidumbre, se posee una alternativa extrema -la cruda violencia de los campos de concentración, la tortura, la muerte- o bien la imposición de estructuras que reduzcan las diferencias a su mínima expresión. Es notable que tres de las instituciones típicas del occidente moderno estén orientadas hacia la homogenización de los comportamientos sociales: el mercado, la división del trabajo y el Estado (Flisfish 1988).

En nuestro tiempo, tales esquemas chocan con una realidad que se nos presenta profundamente fragmentada, incierta y ambigua; ello nos permite caer en la cuenta de que carecemos del instrumental adecuado para interpretarla y analizarla. Esta incertidumbre es una muestra que refleja, a nivel de la experiencia subjetiva, un cambio estructural más profundo. La agudización de la incertidumbre profundiza las dificultades del análisis y hace más evidentes las contradicciones sociales. Esto no es muy novedoso; las sociedades y especialmente las nuestras se ven atravesadas por fuertes contradicciones. Sin embargo, el pensamiento occidental ha buscado desde siempre "EL" principio en torno al cual se articulen las fuerzas sociales. ${ }^{1}$

Ello privilegia una visión monista que reduce la sociedad a una lógica unidimensional. Estas unidimensionalidades se han demostrado insuficientes, y la denominada "crisis de paradigmas" no es sino el reconocimiento de que los procesos sociales no pueden ser reducidos a una racionalidad única.

La incertidumbre frente a la creciente complejidad social que se encuentra en el origen del cuestionamiento de ciertos paradigmas, requiere mirar atentamente el proceso de diferenciación social entendido como de 
constitución de múltiples racionalidades que no aceptan ser reducidas a una sola racionalidad central.

Tal complejidad cuestiona la posibilidad de constituir un orden político democrático, si nos mantenemos en viejos esquemas que asumen la heterogeneidad social como algo problemático (e incluso amenazante) que obstaculiza las posibilidades de desarrollo.

El segundo se refiere a la tensión que introduce el iusnaturalismo. Ya nos hemos referido a las consecuencias de la perspectiva positivista que deja de lado el debate sobre el fundamento del poder reduciendo el problema de la legitimidad a la legalidad existente. Evidentemente, esta posición es marcadamente conservadora. El orden jurídico siempre tiene una relación directa con las estructuras sociales sobre las cuales se construye. Legitimar el orden político por la legalidad existente es favorecer el status quo.

Pero centrémonos en la perspectiva iusnaturalista. En términos generales, su característica de fondo consiste en la imposición dogmática de un modo de legitimidad y de una concepción de la justicia basada en valores considerados universales, inmutables e intemporales.

Planteado en esos términos, la creatividad ética y política de la razón, la voluntad individual y colectiva, el debate ciudadano, pluralista y democrático, encuentran serias dificultades para ser considerados como criterios válidos de legitimidad ya que se enfrentan con el límite que les impone los valores y principios definidos como "naturales".

En este contexto, la soberanía popular y las decisiones fundadas en la regla de la mayoría no pueden ser tenidas en cuenta al momento de definir cuestiones relacionadas con la vida individual, la familia, la política, el orden, la sexualidad, la economía. Los valores y principios así definidos, se hallan por encima de la voluntad y decisión humanas. Llevada al extremo, la concepción iusnaturalista de la legitimidad impone límites y obstáculos injustificados que llevan a desvirtuar, debilitar o negar los fundamentos de la legitimidad democrática.

Hay dos puntos principales que pueden ser objetados: a) la identificación/confusión de la norma jurídica (derecho) con justicia; sólo el derecho justo es derecho y por lo tanto, de manera automática, el derecho y la norma en sí mismos son considerados como justos; b) la imposición -o pretensión de imposición- de un concepto absoluto de justicia dotado de validez intemporal y universal, el cual se utilizará para rechazar toda determinación o decisión contraria a él; incluso si dichos elementos son el resultado de la libre voluntad ciudadana y si se encuentran respaldados por la mayoría, ellos pueden ser considerados como erróneos.

De lo anterior se desprende que la concepción iusnaturalista defiende la existencia de un orden objetivo de justicia que a la vez se presenta 
como un principio de orientación y un límite a todo tipo de poder político, incluso el democrático. En este sentido, es importante destacar que la justificación iusnaturalista del poder puede también ubicarse en la posición de justificar un poder político ilimitado como garantía de obtener el respeto de un orden definido como natural.

Ahora bien, ¿qué significa rechazar la identificación entre justicia y derecho, propia del iusnaturalismo? En primer lugar, significa rescatar la necesidad de conservar la tensión entre derecho y justicia como tensión que permite la actualización permanente de la norma. Si se entiendo la justicia como un proceso siempre inacabado y abierto en el tiempo, resultado de una pluralidad de elementos activados por la conciencia ética y la razón crítica, no existe problema en reconocer que el derecho, resultado de la decisión de la mayoría, puede no coincidir plenamente, en uno o en otro aspecto, en uno u otro momento, con la justicia.

El iusnaturalismo plantea que el problema fundamental en la elaboración del derecho no se encuentra tanto en determinar a quien corresponde la facultad de establecer el derecho formalmente válido -no tiene inconvenientes en reconocer la validez de la representación popular en el marco de un estado de derecho- como en definir a quines corresponde buscar, concretar y transformar lo a priori definido como justo en derecho formalmente (legalmente) válido.

Dicho en otras palabras, el iusnaturalismo no tiene inconvenientes en reconocer que las mayorías tienen el derecho de elegir a las personas responsables de ocupar los cargos gubernamentales; el problema se presenta cuando se trata de definir el contenido real del derecho y a quiénes corresponde definirlo. Tal tarea no es, evidentemente, atributo de la ciudadanía, de las mayorías, ya que la democracia puede legitimar el ejercicio del poder, pero no puede legitimar a priori y por la sólo decisión de la mayoría, las normas que se generan a partir de ese poder.

Una vez elegidas las autoridades (espacio de la libertad), la ciudadanía debe replegarse y dedicarse a obedecer las normas que emanan de ese poder. Normas que por otra parte, son definidas en concordancia con los supuestos naturales por los iusnaturalistas determinados.

Esta concepción se vincula también con las actuales corrientes elitistas de la democracia en tanto prefieren el debate y la reflexión de pequeños grupos que tienen el privilegio de ejercer su libertad y tomar libremente la decisiones, junto con una profunda sospecha por todo aquello que tiene que ver con las decisiones colectivas tomadas de forma mas participativa.

Ello va acompañado de un juicio profundamente negativo de la democracia. Ella se asocia a la generación de una creciente inseguridad jurídica e inestabilidad institucional, favorable a la acción revolucionaria y a los cambios rápidos. 
La respuesta que se plantea como una solución a tales inconvenientes tendencias es la de constituir un régimen político mixto en donde se combinen equilibradamente los elementos monárquicos, aristocráticos y democráticos. A lo democrático le corresponde elegir a las autoridades; a lo monárquico-aristocrático, supervisar que las leyes formales se encuentren en concordancia con los principios naturales.

En conclusión. La justicia no depende las mayorías o de la soberanía popular, pero por esta vía de reconocer mas libertades y mayor diversidad de racionalidades, puede haber mas justicia que si dejamos que se impongan los criterios de intereses individuales o de grupos.

En síntesis, esquemáticamente, tanto el positivismo como iusnaturalismo, coinciden en un punto: en rechazar, por recorridos distintos, la tensión entre legitimidad y legalidad. El primero porque considera que todo lo legalmente establecido -mas aún en democracia- es legítimo; el segundo, porque lo legítimo ya se encuentra establecido, y que no queda mas tarea que traducirlo en ley.

Los reforzamientos a que hacíamos referencia mas arriba operan, el primero, en el sentido de desconocer o rechazar las diferencias y a pensar la sociedad bajo un esquema de buenos y malos donde los buenos obedecen la ley y los otros la desobedecen; en este sentido, todo y cualquier intento de desobediencia será considerado como negativo; el segundo, porque tanto desde el positivismo como desde el iusnaturalismo, no se puede aceptar ninguna “cuña” que tensione las relaciones entre legitimidad y legalidad: si todo lo legal es legítimo, todo comportamiento no-legal es a priori ilegítimo.

\section{Sobre el concepto de desobediencia civil}

Debemos aquí retomar lo manifestado en este segundo punto antes de introducirnos en el análisis teórico de la desobediencia civil. Y en este sentido, me parece importante secar algunas conclusiones provisorias:

a) ya no es posible -si es que lo fue en alguna época- apostar a que el funcionamiento de las instituciones democráticas garantiza de por sí la vigencia de un estado de derecho

b) que como producto de las características que ha adquirido el sistema político -especialmente el sistema de partidos- es posible esperar en el futuro una mayor tensión entre la legalidad de las normas y su legitimidad; es decir, una crisis de legitimidad.

c) que los esquemas predominantes tanto en el campo político, como en el de las ciencias sociales y jurídicas, fundamentalmente binarios y que remiten a una noción preconstituída de lo bueno, lo justo y lo deseable, dificultan una valoración distinta de las actos de desobe- 
diencia, y en definitiva de la democracia.

Entre quienes abordan el análisis de la desobediencia civil se encuentra Hannah Arendt quien ubica el problema en el plano de la "relación moral del ciudadano con la ley en una sociedad de asentimiento" (Arendt 1988: 59), definiéndola como la manifestación de "minorías organizadas unidas por una opinión común mas que por un interés común y por la decisión de adoptar una postura contra la política de gobierno, aunque tengan razón para suponer que semejante política goza del apoyo de la mayoría; su acción concertada proviene de un acuerdo entre ellos, y es este acuerdo lo que presta crédito y convicción a su opinión, sea cual fuere la forma en que la hayan alcanzado" (Ibid: 64).

Por ello descarta un abordaje del fenómeno desde el plano de la conciencia individual (de los actos individuales), porque, ya sea que estos se definan como imperativos morales o como recurso a una ley más alta de carácter trascendente o secular, es necesario que ella cumpla un requisito que cambia radicalmente su calidad: debe transformarse en opinión pública. Vemos aquí una primera diferencia con la acción de Thoreau que era individual.

El hecho que la desobediencia se haya convertido en un fenómeno generalizado de alcance mundial cada vez mas frecuente es una muestra de lo que podría ser considerado una creciente pérdida de legitimidad de la ley. Arendt afirma que la ello surge "cuando un significativo número de ciudadanos ha llegado a convencerse o bien que ya no funcionan los canales normales de cambio y de que sus quejas no serán oídas o no darán lugar a acciones ulteriores, o bien, por el contrario, de que el gobierno está a punto de cambiar y se ha embarcado y persiste en modos acción cuya legalidad y constitucionalidad quedan abiertas a grandes dudas” (Ibid: 82).

A fin de aportar mayor claridad al concepto de desobediencia, Arendt precisa sus diferencias con otras dos nociones con las cuales a veces se la confunde: la delincuencia y la acción revolucionaria. Mientras la desobediencia es un desafío abierto a la ley que se desarrolla en el ámbito público con el objetivo de hacer conocer un disentimiento básico representativo del sentimiento de un grupo, la delincuencia es el resultado de la erosión del poder, sumada a la incompetencia de la policía. Además, y esto es lo fundamental, la delincuencia se realiza de manera "oculta” persiguiendo un beneficio personal.

¿Cual es la diferencia con la acción revolucionaria? Se distinguen en que la desobediencia no es violenta y reconoce el Estado de derecho y la constitucionalidad vigente en sus rasgos fundamentales mientras que la acción revolucionaria recurre a la violencia como una manera de expresar su rechazo al conjunto del ordenamiento vigente. Arendt reconoce, sin embargo, que ambas coinciden en sus deseos de cambiar el mundo.

La pregunta que surge es como compatibilizar desobediencia con 
ley o, como se pregunta la autora, qué concepto de ley necesitamos tener para hacer compatible la desobediencia. Y la compatibilidad es posible porque la desobediencia es una acción extralegal que se orienta hacia la constitución de una nueva legalidad. En la perspectiva contractualista de Arendt, la desobediencia es una forma de actualizar efectivamente los contenidos del contrato “originario" que define desde la soberanía popular el contenido específico de la relación de mando y obediencia.

Desde otra perspectiva Habermas (1988) descarta la confusión un tanto extendida entre desobediencia y delincuencia y terrorismo. En el marco del análisis que Habermas elabora respecto a los regimenes democráticos y sociedades capitalistas modernas, sostiene que la desobediencia civil se presenta como una salida frente a la crisis de legitimidad de los sistemas políticos y a la obstrucción de los canales legales de participación. ${ }^{2}$

Salida aun más valiosa cuando la profundidad de la crisis nos hace sospechar que el accionar de los nuevos movimientos sociales apunta a un cuestionamiento de fondo: no se trata de "maquillar" el proceso de desarrollo, sino de cambiar su estilo.

Sin embargo, estas demandas son interpretadas como simple delincuencia, lo cual a su vez refuerza las exigencias de mano dura (y en ocasiones, de "gatillo fácil") y descarta la posibilidad de considerarlas como componentes "normales" de una cultura política madura, de ciudadanos que respetan la constitución y de un Estado de derecho fortalecido.

Justifica en algo las sospechas frente a este tipo de manifestaciones ya que en el pasado los movimientos de protesta estaban inspirados en falsos tópicos revolucionarios descartando la adhesión a los principios constitucionales democráticos. Pero olvida que la desobediencia es "una protesta moralmente fundada en cuyo origen no tienen porque encontrarse tan solo convicciones sobre creencias privadas o ni intereses propios; se trata de un acto público, que por regla general, es anunciado de antemano y cuya ejecución es conocida y calculada por la policía; incluye un propósito de violación de normas jurídicas concretas, sin poner en cuestión la obediencia frente al ordenamiento jurídico en su conjunto; requiere la disposición de admitir las consecuencias que acarrea la violación de la norma jurídica; la violación de la norma que es una manifestación de la desobediencia civil, tiene exclusivamente un carácter simbólico: aquí es donde reside el límite de los métodos no violentos de protesta” (Habermas 1988: 56).

Los nuevos movimientos sociales tienen el "convencimiento de que los actos de protestas, aun cuando suponen golpes calculados, no pueden tener mas que un carácter simbólico y solo deben poder llevarse a cabo con la intención de apelar a la capacidad de comprensión y al sentido del derecho de la correspondiente mayoría.” (Ibid: 54)

Pero, ¿desde donde apelar? Evidentemente, la apelación no puede recurrir al derecho positivo y por lo tanto, la justificación de la desobedien- 
cia a las leyes debe apoyarse en el reconocimiento de que existen otros principios de legitimación más allá de la mera legalidad. Este principio, según Habermas, está ligado a un procedimiento de configuración razonada de las voluntades que fundamenten la obediencia en un reconocimiento juicioso y voluntario que supone una construcción comunicativa e intersubjetiva del orden social.

Dworkin (1992) aborda el tratamiento de la desobediencia civil a partir del análisis de aquellos que desobedecen las leyes de reclutamiento para realizar el servicio militar. Sostiene que los motivos que habitualmente se esgrimen para rechazar la desobediencia son menos fuertes de lo que se piensa; se dice que si se tolera la desobediencia, esto generaría caos y anarquía. Al respecto hace tres precisiones: primero, que no se trata de una desobediencia generalizada al conjunto de leyes, y que por lo tanto no ve cómo la desobediencia a alguna de sus normas puede desmoronar toda andamiaje legal; segundo, al menos en el caso de los Estados Unidos, un fiscal tiene facultades para no presentar cargos cuando encuentra razones de peso que así lo justifiquen; tercero, los motivos del desobediente son mas altruistas que el del simple delincuente o del ciudadano que se mueve por sus propios intereses; cuarto, enjuiciando a los desobedientes, la sociedad margina a algunos de sus mejores ciudadanos incrementando el grado de su alienación.

Solo es posible desechar la desobediencia si encontramos buenas razones para dejar de considerar los argumentos anteriormente enumerados.

Aquí se presenta un punto decisivo: se sabe que una ley puede no ser válida por ser inconstitucional. Lo que se deduce es que si una ley es inconstitucional, ella es inválida; si es constitucional, es válida; en el primer caso no es delito violarla y por lo tanto no hay castigo, mientras que en el segundo procede lo contrario. Lo que este razonamiento elude, y que Dworkin señala como bastante frecuente, es que la validez de una norma puede ser dudosa, existiendo argumento en los dos sentidos.

Esto es decisivo, porque abre la posibilidad que una norma no siendo claramente inconstitucional, presente serias dudas de ello a un conjunto de ciudadanos que mientras más grande, mas razón podrá tener. La pregunta es que deben hacer esos ciudadanos ente estas situaciones.

En este sentido, frente a una ley dudosa, Dworkin describe tres posibles situaciones: a) que suponga que la ley se lo prohíbe; b) que persista en su duda hasta que la situación sea decidida por un tribunal competente; c) que incluso frente a la decisión de un tribunal en contrario que falle en su contra, el ciudadano persista en su actitud, claro que teniendo en cuenta los argumentos de los precedentes.

De entrada descarta un tipo de comportamiento como el primero, no solo porque no ve razones para no hacer aquello que la ley no prohíbe sino 
porque además se perdería la ventaja de útiles pruebas que revelan que sucede efectivamente cuando ello sucede. Respecto al segundo proceder, señala que no tiene en cuenta que cualquier tribunal puede desestimar sus propias decisiones, y que por lo tanto, si un ciudadano puede seguir pensando conscientemente que el derecho está de su parte y obrar coherentemente con ella; incluso si tiene una expectativa razonable para pensar que el tribunal puede cambiar su posición en un futuro cercano.

Queda claro que para Dworkin la tercera alternativa es la correcta, ya que cuando una ley es de dudosa validez, no comete una injusticia el ciudadano que defiende sus posiciones incluso luego de un fallo de un tribunal superior. A menos que insistamos tozudamente en identificar al ciudadano que actúa según su propio juicio respecto a una ley dudosa con el delincuente, no existen razones para no moderar la firmeza de la sentencia que la ley es la ley: “cuando las razones prácticas para enjuiciar son relativamente débiles en un caso determinado, o se las puede cumplir de otras maneras, la senda de la equidad pasa por la tolerancia.” (Dworkin 1992: 316)

Rawls (1985) sostiene que el deber de fomentar las instituciones justas tiene un doble aspecto: por una parte, nos obliga a obedecer las instituciones que son justas, y por otra parte, nos obliga a fomentar el establecimiento de instituciones justas. De ello se deriva el deber natural de obedecer lo que la ley exige, el cual a su vez deriva de un principio que Rawls considera como fundamental: el de imparcialidad.

Este principio expresa que "una persona está obligada a cumplir su parte, como lo establecen las normas de la institución, cuando ha aceptado voluntariamente los beneficios del esquema institucional, o se ha beneficiado de las oportunidades que ofrece para fomentar sus intereses, supuesto que esta institución sea justa o imparcial, es decir, satisfaga los dos principios de la justicia.” (Rawls 1985: 383) Es decir, todo lo justa o imparcial que es razonable de acuerdo a las circunstancias.

Se presenta como casi una obviedad el deber de obedecer leyes considerados justas. Las preguntas surgen cuando sucede lo contrario: ¿por qué debemos obedecer leyes injustas? y ¿por qué podemos desobedecerlas? La respuesta afirmativa al primero de ellos se justifica en la existencia de una estructura político-social razonablemente justa. Es decir, ante la duda y siempre y cuando no se superen ciertos límites de injusticia, el ciudadano debe obedecer la ley. Existen razones para pensar que, en un caso como este en donde las normas son el resultado de la aplicación de la regla de mayorías, éste es el método más eficaz para constituir normas justas al menos considerándolo en su balance general.

En lo que respecta a la segunda, Rawls acepta la desobediencia según sea la extensión de la injusticia (normas e instituciones y programas políticos). Señala dos caminos por medio de los cuales puede producirse la injusticia: "los acuerdos existentes pueden diferir en varios grados de las 
normas públicamente aceptadas, que son mas o menos justas; o puede que estos acuerdos se adecuen a la concepción de justicia que tenga una sociedad, o al punto de vista de la clase dominante, pero esta concepción puede ser irracional por sí misma, y en muchos caso claramente injusta.” (Ibid: 392)

Define la desobediencia civil como "un acto público, no violento, consciente y político, contrario a la ley, cometido con el propósito de ocasionar un cambio en la ley o en los programas de gobierno” (Ibid: 405) apelando al sentido de justicia de la sociedad, todo ello cuando consideramos que no se respetan los principios de justicia.

Mas adelante precisa: la desobediencia es un acto político no solo porque se dirige a la mayoría poderosa, sino porque se fundamenta en razones políticas; es también un acto público en un dobles sentido: se dirige a principios públicos y se comete en público; es también un acto no-violento, ya sea porque rechaza ese medio, ya sea porque se expresa dentro de los límites de la fidelidad a la ley. ${ }^{3}$

Las condiciones para el ejercicio de la desobediencia civil son fundamentalmente tres: a) debe limitarse a casos claramente injustos originados en la violación de la libertad igual y de la igualdad de oportunidades; b) debe ser considerada como un último recurso, y en este sentido, es preferible (aunque no siempre) que sean agotados todos los recursos legales; c) debe tenerse en cuenta las restricciones que se derivan de un ejercicio abusivo de este camino, ya que si bien el orden puede soportar algunas desobediencias, su exagerada multiplicación puede realmente desembocar en el caos y en un rendimiento decreciente: "si todos ejercitamos este derecho, sobrevendrán consecuencias nocivas para todos” (Ibid: 417).

Pero tal vez lo más importante sea el análisis del sentido de la desobediencia civil en el contexto de un régimen democrático-constitucional. En él, ella opera como un recurso ilegal estabilizador de un sistema de cooperación (la sociedad) cuando éste se ha visto sometido a fuertes desequilibrios expresados en injusticias graves; "es un medio moral correcto para mantener el régimen constitucional (...), es una parte de la teoría del libre gobierno (...), es un medio normalmente razonable y eficaz de protestar regulada de algún modo por un sentido de la justicia” (Ibid: 422).

Singer (1985) establece que la desobediencia civil es un desafío a la ley, con fundamento moral, cuyos argumentos deben ser analizados en el contexto concreto de las razones para obedecer que presenta un régimen democrático.

En este sentido, analiza cuatro formas de desobediencia:

a) derechos en contra de la mayoría: si la democracia supone el respeto de los derechos de las minorías, es lógico suponer que las acciones de las mayorías deben estar sujetas a ciertos límites. Cuando 
ello no sucede, y las mayorías atropellan los derechos individuales o de grupos minoritarios, nos encontramos frente a normas que carecen de autoridad moral para ser obedecidas; la desobediencia es válida cuando el procedimiento de toma de decisiones considerado como un compromiso justo se rompe.

b) desobediencia por publicidad: se trata de hacer públicas las razones del disentimiento con el objetivo de buscar audiencia justa para dar a conocer los motivos de la desobediencia. Es un medio de persuasión. El interrogante que surge es como asegurar una audiencia justa para el grupo desobediente.

c) desobediencia como alegato de reconsideración: busca instar a la mayoría a que reconsidere una decisión que se ha tomado. Por lo general, se recurre al mecanismo de referéndum, pero en caso de que este no prospere se justifica la desobediencia.

d) objeción de conciencia: es una modalidad de desobediencia no coercitiva y coherente con los principios democráticos. Se propone evitar los efectos que genera una norma que se objeta, pero no conseguir que esta cambie. Singer reconoce que respecto de la pregunta qué es la conciencia, no existe mucha claridad. Sin embargo, señala que es posible distinguir dos tipos de conciencia, una tradicional y otra crítica, y sólo la desobediencia es válida en el caso de la segunda. ¿Por qué? Porque solo allí el individuo actúa como agente racional.

\section{A modo de conclusión}

¿Cuál puede ser la relevancia de abordar el análisis de la desobediencia civil en el contexto de la sociedad chilena actual? Desde un primer punto de vista, rescato el aporte que desde la teoría de la desobediencia civil se hace de la capacidad de los ciudadanos para cuestionar la legalidad vigente apelando a un sentido de la justicia que debe ser validado en el espacio público. Considero que ello representa el significado más profundo de la democracia en el sentido de que ella es, en una de sus interpretaciones, una forma de autogobierno en donde el poder solo se delega (siempre precariamente) a los representantes.

Es, al mismo tiempo, una posibilidad de ejercer reflexivamente ese poder incluso en contra de los definidos legalmente en el derecho positivo. Ello nos recuerda, de paso, que el derecho no es algo natural sino el resultado de conflictos de poder en donde triunfan aquellas interpretaciones que cuentan con mayores recursos políticos para transformarse en norma positiva.

Finalmente, si es cierto que existe una crisis de representación de los partidos políticos, prácticas de desobediencia civil significan una manera de autorrepresentación en sociedades cada vez más complejas. 
Desde la perspectiva de nuestra realidad chilena y latinoamericana considero que el aporte es significativo por tres razones adicionales. En primer lugar, vivimos en sociedades atravesadas por un profundo déficit democrático. Los niveles de inequidad social y político permiten incluso cuestionar, en algunos casos, la real vigencia de un régimen político democrático.

En segundo lugar, nuestras sociedades experimentan un proceso de creciente complejización con un sistema político que no logra un grado de innovación institucional que permita una expresión "ordenada” de intereses cada vez más diversos y contradictorios. Esto explica en parte las dificultades de los partidos políticos para representar adecuadamente a la sociedad.

La combinación de una institucionalidad simple y precaria (podemos tomar como ejemplo el lento e irritante proceso de innovación en materia de participación ciudadana o de democratización de los gobiernos regionales incluso en un aspecto bastante poco "radical” como lo es la elección popular de los consejeros regionales) con una sociedad cada vez más diversa y compleja genera tensiones (en una sociedad en donde, además, la justificación del orden político tiene una fuerte carga autoritaria) que transgreden los límites de de los legalmente permitido.

En un escenario así, conductas como estas tienden a ser interpretadas como simples desafíos a la institucionalidad homologables a conductas delincuenciales. De esta manera, el estado democrático de derecho se pierde la oportunidad de revisar el significado más profundo de esas prácticas y de sus respuestas a ellas que siguen respondiendo al esquema habitual de represión policial de todo acto ilegal. 


\section{Notas}

${ }^{1}$ En este punto seguimos la reflexión que Norbert Lechner realiza en Los desafíos de la ciencias sociales en América Latina, FLACSO, Santiago, Documento de Trabajo, Nro. 372, 1988.

${ }^{2}$ Habermas reconoce tres sistemas fundamentales: el económico, el administrativo y el de legitimidad. El primer sistema está constituido por un sector privado (sector competitivo + sector oligopólico) y otro público. Se vincula con el segundo, ya que es el sistema administrativo el que interviene en la economía regulándola y estableciendo condiciones para la valorización del capital. Pero el más importante de los tres es el sistema de legitimación. Producto de la "repolitización" de las relaciones de producción, las intervenciones del Estado en la economía deben ser legitimadas por medio de los mecanismos de la democracia formal. Pero estos mecanismos permiten, por una parte, una participación política limitada, y por otra parte, una gran libertad de acción al sistema administrativo de tal modo que éste se vincula con el sistema económico autónomamente de la voluntad ciudadana. En el contexto de un espacio público estructuralmente despolitizado, los ciudadanos "adquieren el status de ciudadanos pasivos con derecho a aprobación o rechazo en bloque de los hechos consumados.” ${ }^{2}$ De la situación antes descrita se derivan tendencias a la crisis en diversos ámbitos; tendencia a la crisis económica, a la crisis política, a la crisis socio-cultural. Específicamente, la crisis político-administrativa es una crisis que se manifiesta como crisis de racionalidad (crisis de los outputs que ya no logran conciliar los imperativos de autogobierno que se originan en el sistema económico), y como crisis de legitimidad (de los inputs, es decir, que el sistema ya no logra generar lealtades al "arreglo" el sistema económico y administrativo). El origen de la crisis de legitimidad (de la lealtad de masas) es una crisis de identidad generada en el cuestionamiento que aquel "arreglo" coloca sobre un espacio público despolitizado y en la democracia como régimen de control del sistema económico. Habermas, Jurgen, Crisis de legitimación en el capitalismo tardío, Amorrortu, Buenos Aires, 1987, pags. 19 y 54.

${ }^{3}$ Rawls considera en una categoría aparte a la objeción de conciencia, la que define como el no consentimiento de un mandato legislativo mas o menos directo, o de una orden administrativa; no apela al sentimiento de justicia de la sociedad, no se basa únicamente en principios políticos (pueden ser religiosos). 


\section{Bibliografía}

Arendt, H. (1988), La crisis de la república, Taurus, Madrid.

Bobbio, N. (1988), El futuro de la democracia, FCE, México.

Ídem (2006), Estado, gobierno y sociedad, FCE, México.

Del Aguila, R. (1997), Manual de ciencia política, Trotta, Madrid.

Dworkin, R. (1992), Los derechos en serio, Ariel, Barcelona.

Flisfish, A. (1988), La democracia como compromiso democrático, FLACSO, Santiago.

Foucault, M. (1978), Microfísica del poder, Ediciones de la Piqueta, Madrid.

Habermas, J. (1988), Ensayos políticos, Península, Barcelona.

Ídem (1987), Crisis de legitimación en el capitalismo tardío, Amorrortu, Buenos Aires.

Lechner, N. (1984), ¿Qué significa hacer política?, FLACSO, Santiago.

Ídem (1988), Los desafíos de la ciencias sociales en América Latina, FLACSO, Santiago, Documento de Trabajo, Nro. 372.

Loewenstein, K.(1983), Teoría de la constitución, Ariel, Barcelona.

Muñoz, O. (1993), Hacia el estado regulador, CIEPLAN, Santiago.

Rawls, J. (1985), Teoría de la justicia, FCE, México.

Singer, P. (1985), Democracia y desobediencia, Ariel, Barcelona.

Tenzer, N. (1991), La sociedad despolitizada, Paidós, Buenos Aires.

Thoreau, H. (2006), Desobediencia civil, Leviatán, Buenos Aires.

Weber, M. (1988), Economía y sociedad, FCE, México.

Recibido: 10.08.2009

Aceptado: 05.05.2010 